\title{
Treaty calls time on long-term pollutants
}

Jim Giles, London

The clock is ticking for a troublesome set of chemical pollutants. Last week, a three-month countdown began towards the day when the Stockholm Convention on Persistent Organic Pollutants (POPs) comes into force.

But environmental-health specialists warn that the first phase of the agreement, drawn up in 2001, represents a relatively easy win. From May, the convention will ban the use of 12 types of pollutant of limited economic importance; but subsequent constraints on more financially valuable compounds will be fiercely fought by chemical manufacturers, the specialists predict.

The countdown towards implementation was triggered on 17 February, when France became the fiftieth country to ratify the agreement. Several countries, including the
United States and Britain, have yet to ratify it, but are preparing legislation to do so.

Environmentalists have campaigned for years against POPs, a group of very stable compounds that includes dioxins and the pesticide chlordane. POPs accumulate in animals and plants at the end of the food chain, and have been linked to a range of human health problems.

Chemical manufacturers accept that the 12 substances covered by the first phase of the convention are dangerous, and have already phased some of them out. But Bo Wahlstrom, a Geneva-based scientific adviser at the United Nations Environment Programme, which brokered the treaty, predicts that it will be far harder to incorporate compounds that are still made and sold in large quantities.

Substances that are likely to spark disagreement include brominated flame retar-

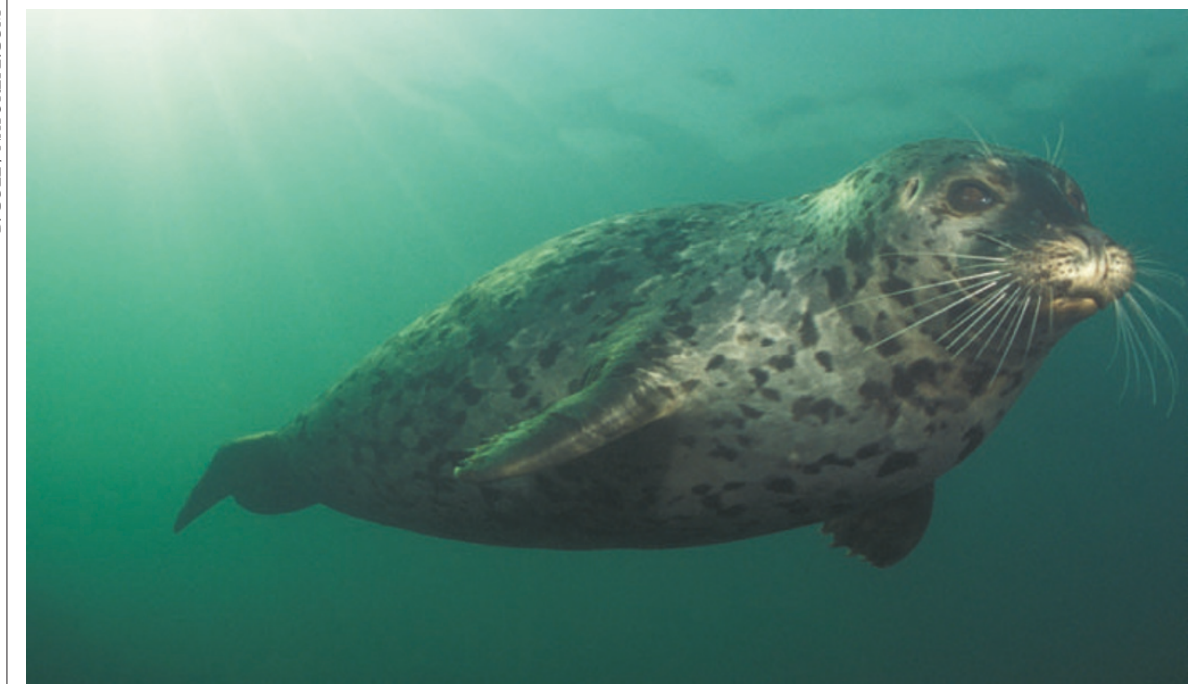

Harbour seals are among the creatures in which persistent organic pollutants may accumulate. dants such as hexabromocyclododecane (HBCD) and decabromodiphenyl ether (decaBDE). Tens of thousands of tonnes of these compounds are made every year, primarily as flame-retarding additives for textiles, electrical equipment and building materials. The retardants can enter the environment during manufacture and disposal, and their stability means that they can build up in humans and animals over time.

The jury is still out on whether the current level of exposure to these compounds presents a health risk to people and animals, say environmental-health researchers. But, they add, HBCD and decaBDE meet some of the criteria for being classed as POPs.

Steve Robinson, chemicals assessment manager at the Environment Agency in Wallingford, near Oxford, UK, says that $\mathrm{HBCD}$ is toxic and accumulates in living tissue. He adds that industry is now running tests to assess another criterion for it to be classed as a POP: whether or not it persists in the environment. So far, the only evidence for decaBDE as a possible POP is that it has been shown to build up in the tissue of animals at the end of the food chain, such as harbour seals, birds of prey and dolphins (L. S. Birnbaum and D. F. Staskal Environ. Health Perspect. 112, 9-17; 2004).

The status of such contentious compounds will become clear when European Union nations complete a risk assessment of flame retardants later this summer. The Bromine Science and Environment Forum, which represents bromine manufacturers, says that the industry is working with officials on this assessment and that, so far, the studies show no need for decaBDE or HBCD to be added to the convention.

www.pops.int

\section{Closure threat propels astronomers to institute's aid}

\section{Quirin Schiermeier, Munich}

Top astronomers are protesting that a proposal to close the Astronomical Institute at the University of Basle in Switzerland ignores the institute's strong track record in research.

The university's governing council recommended on 22 January that the department, along with the university's institutes of geology and Slavic studies, should close by 2008 .

Rolf Soiron, the businessman who chairs the council, says that the closures were needed to consolidate finances and avoid duplication of training and research facilities in Switzerland.

The Swiss government, which supports the consolidation of small university departments, has backed the plan. "It is a courageous and exemplary move," says Charles Kleiber, the Swiss state secretary for education and science.

But astronomers are complaining that the decision was made in response to low student numbers, without any external scientific assessment of the institute's performance. In letters to Soiron, more than 100 astronomers from around the world protested against the decision.

The institute has "produced by far the most careful and thorough dynamical models of the Milky Way that are available anywhere in the world", wrote Scott Tremaine, chair of astrophysical sciences at
Princeton University, New Jersey. Astronomers also criticized the treatment of Eva Grebel, a rising star among galactic astronomers, who won tenure at the institute only last September.

"People will think that in Switzerland you can easily lose your job, even though you are tenured. This is a blow to our reputation," says Willy Benz, an astrophysicist at the University of Berne and a member of the Swiss Science and Technology Council.

The university defends the plan. "This was not done in a rush. The board spent months coming up with a balanced reform," says Maria Schoch, a spokeswoman for the rector. 